\title{
Mais capacidade estatal, menos corrupção? Uma análise para a América Latina (1996-2015)
}

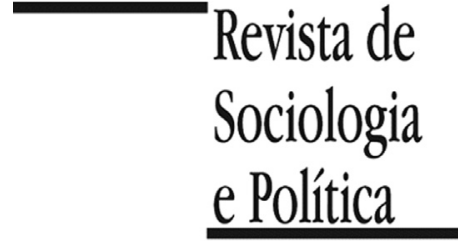

DOI $10.1590 / 1678987318266806$

\section{Luma Neto do Nascimento ic}

RESUMO Introdução: Quanto maior a capacidade estatal, menor a corrupção? O presente trabalho testa a hipótese de que a capacidade estatal diminui os níveis de corrupção na América Latina no período entre os anos de 1996 e 2015. Materiais e Métodos: Para um teste de robustez, o nível de ausência da corrupção foi medido através de dois índices diferentes, o índice CPI da ONG Transparência Internacional e o índice CCI do Banco Mundial. A capacidade estatal foi medida através da arrecadação de impostos como porcentagem do PIB; a capacidade coercitiva do Estado foi medida através das despesas militares como porcentagem do PIB; a capacidade administrativa foi medida através do índice de qualidade burocrática do ICRG. Para os testes de hipóteses foram estimados dois painéis de dados PCSE, um com o CPI como variável dependente e outro com o CCI como variável dependente. Resultados: Os resultados sugerem que a principal hipótese foi confirmada: a capacidade estatal aumenta os níveis de ausência de corrupção, mesmo após o teste de robustez para as duas medidas de ausência de corrupção e com controles para possíveis determinantes políticas e socioeconômicas da corrupção sugeridas pela literatura. Entretanto, a medida de capacidade administrativa só obteve significância com o índice CCI como variável dependente. Discussão: Esta pesquisa irá contribuir para a literatura ao analisar um novo determinante da corrupção, a capacidade estatal, mostrando que esta deve ser incluída nos estudos que pretendem analisar suas causas.

PALAVRAS-CHAVE: capacidade estatal; capacidade administrativa; capacidade coercitiva; corrupção; América Latina.

Recebido em 12 de Agosto de 2017. Aceito em 17 de Fevereiro de 2018.

\section{Introdução ${ }^{1}$}

${ }^{1}$ Agradeço os comentários e sugestões dos pareceristas anônimos da Revista de Sociologia e Política.
$\mathrm{Q}$ uanto maior a capacidade estatal, menor a corrupção? Problemas de baixa capacidade do Estado são especialmente relevantes em países em desenvolvimento. Observadores, como Todaro e Smith (2015, p.815), argumentam que "a capacidade público-administrativa é o recurso mais escasso no mundo em desenvolvimento". Estados eficazes são cruciais para o controle da corrupção porque detêm o monopólio da força, a burocracia e os recursos para o combate às atividades criminosas (Acemoglu \& Robinson 2015, p.71; Mainwaring \& Pérez-Liñán 2015, p.124). E, apesar de a maioria dos governos da América Latina serem produtos genuínos de eleições livres e inclusivas, poucos resistem à tentação de abusar de seus poderes para fins particulares, com a exceção do Chile, Uruguai e Costa Rica (Mazzuca 2010, p.335). Os partidos no poder mudam, mas os escândalos de corrupção continuam a envolver líderes nacionais e locais, grupos econômicos e organizações criminosas. Assim, é importante examinar se o aparelho estatal pode contribuir para diminuir as atividades corruptas, especialmente no que diz respeito à região latino-americana.

A literatura sobre a capacidade do Estado apresenta várias definições (Hendrix 2010), mas uma noção bastante comum refere-se à capacidade de o Estado "penetrar na sociedade, regular as relações sociais, extrair recursos e apropriar-se ou usar esses recursos de maneiras determinadas" (Migdal 1988, p.4).

A capacidade estatal tem pelo menos três dimensões: 1) capacidade extrativa; (2) capacidade administrativa e (3) capacidade coercitiva (Hanson \& 
Sigman 2013). Um governo efetivamente capaz em todas elas é condição necessária para o bem-estar social, onde se inclui segurança, ordem política e crescimento econômico (Evans \& Rauch 1999; Rothstein \& Teorell 2008, p.166; Fukuyama 2004).

Segundo Hanson e Sigman (2013, p.4), a capacidade extrativa reflete "a capacidade de alcançar a população, coletar e gerenciar informações, possuir agentes confiáveis para gerenciar a receita e garantir o cumprimento da política tributária". A capacidade administrativa, por sua vez, refere-se à "habilidade de desenvolver políticas, produzir e entregar bens e serviços públicos, além de regular a atividade comercial". Para que um Estado possua esse tipo de capacidade, é necessária a existência de competência técnica, agentes confiáveis e profissionais, e monitoramento e extensão de todos esses fatores por todo o território. Por fim, a capacidade coercitiva refere-se "à capacidade de preservar fronteiras, proteger-se de ameaças externas, manter a ordem interna e conter a violência".

A definição de corrupção mais aceita pela literatura é o abuso de poder público para ganhos privados (Voigt \& Gutmann 2015; Jong-sung \& Khagram 2005). A literatura aponta diversos determinantes econômicos, políticos e socioculturais para as atividades corruptas. Porém, verificou-se uma lacuna sobre os impactos dos aparelhos estatais nos graus de corrupção. Os poucos trabalhos disponíveis (Rauch \& Evans 2000; Dahlström et al., 2009; 2012; Charron et al., 2017; D’Arcy \& Nistotskaya 2017) abordaram apenas a dimensão administrativa da capacidade do Estado como determinante do abuso do poder público para ganhos privados. Especialmente, este é o primeiro estudo de corte transversal e série temporal a estimar o impacto das três dimensões básicas da capacidade estatal sobre o grau de controle da corrupção.

O estudo apresenta um arcabouço teórico que explica (1) por que a capacidade do Estado serve para controlar a corrupção e (2) por que a dimensão coercitiva é a mais importante. Para os testes das hipóteses, foram montados dois painéis de dados com o estimador Panel Corrected Standard Errors (PCSE), cada qual com uma variável dependente:

1) Índice de Percepção da Corrupção da Transparência Internacional (Corruption Perceptions Index - CPI);

2) Índice de Controle da Corrupção do Banco Mundial (Control of Corruption Index - CCI), para um teste de robustez.

Os indicadores utilizados para medir as diferentes dimensões da capacidade estatal foram:

1) A arrecadação de impostos em porcentagem do PIB, como medida da capacidade extrativa do Estado;

2) As despesas militares em porcentagem do PIB, como medida da capacidade coercitiva;

3) O Índice de Qualidade Burocrática do ICRG (International Country Risk Guide), como medida de capacidade administrativa.

Os resultados mostram que a capacidade estatal aumenta os graus de controle da corrupção, sendo robustos tanto para os Índices CPI e CCI (as variáveis dependentes), como também para o controle das variáveis sugeridas pela literatura pela literatura como de possível impacto sobre os graus de corrupção. A expectativa de que a capacidade coercitiva seja um preditor mais robusto em relação às outras dimensões da capacidade estatal se concretizou. Isso revela que os atuais estudos negligenciaram este aspecto fundamental do Estado: manter o monopólio efetivo do uso da força (Weber 1967). Porém, os 
resultados devem ser interpretados com cautela, pois a medida de capacidade administrativa só obteve significância estatística com o Índice CCI.

O presente trabalho está dividido em três seções e uma conclusão. A primeira seção faz uma breve revisão do referencial teórico utilizado. A segunda descreve os dados e a metodologia empregada. A terceira apresenta os resultados da estatística descritiva e do estimador PCSE. Por fim, a conclusão resume os resultados e propõe uma agenda para futuras pesquisas.

\section{Referencial Teórico}

Huntington (1968) foi um dos primeiros estudiosos a alertar para os riscos da chamada "democratização prematura" ou "sequência reversa" entre países durante a Segunda Onda de Democratização, nos anos 1960: países em que a democracia se estabeleceu antes da construção de um Estado forte sofreram com conflitos sociais violentos, golpes militares, redes de patronagem e clientelismo. Desde então, uma extensa literatura abordou a relação entre capacidade estatal e democracia (Mazzuca \& Munck 2014; Fortin 2012; Bunce 2000; Fukuyama 2004; 2013; 2014; 2015; Andersen et al., 2014; Holmes 1997; Huber, Rueschemeyer \& Stephens 1999; Linz \& Stepan 1996; Przeworski 1995; Roberts \& Sherlock 1999; Suleiman 1999; Tilly 2007; Wang 1999). Entretanto, ainda há poucas evidências sobre o papel do Estado no principal sintoma de um déficit democrático: a corrupção (Linz \& Stepan 1996; O'Donnell, Vargas \& Iazzetta 2004; Diamond \& Morlino 2005; Beetham et al., 2008).

A era atual de transições democráticas constitui a Terceira Onda de Democratização no mundo moderno. Entre 1974 e 1990, pelo menos 30 países se democratizaram, praticamente dobrando o número de governos democráticos no planeta (Huntington 1991); hoje, a maioria dos países podem ser categorizados como democráticos (Møller \& Skaaning 2013, p.77). O legado da Terceira Onda na América Latina é um conjunto de regimes políticos em que os governos são formados por meios democráticos, mas presidentes, governadores, legisladores e juízes promovem ou protegem a exploração de cargos públicos para fins privados (Mazzuca 2010, p.335). Portanto, estudar o impacto da capacidade estatal na democracia em seu sentido mínimo, ou seja, como forma de acesso ao poder (Mazzuca 2010, p.334) não é suficiente. É preciso analisar até que ponto Estados mais fortes podem colaborar para a qualidade do exercício do poder, isto é, para governos menos corruptos.

Apesar de argumentar que nenhuma democracia pode funcionar se o Estado não tiver capacidade de supervisionar as tomadas de decisão e colocar seus resultados em prática, Tilly (2007, pp.15-17) entende que a relação entre capacidade estatal e democracia pode ser não-linear. Um Estado com extrema capacidade pode permitir que os governantes minem a democratização. Por exemplo, o mais alto grau de capacidade estatal da Venezuela aconteceu durante o governo de Hugo Chávez. Porém, isto ocorreu acompanhado de um retrocesso democrático. Chávez usou seu controle sobre as receitas do petróleo para consolidar seu poder, reprimir a oposição e patrocinar o populismo em outros lugares da América Latina (Tilly 2007, pp.170-172). Já Estados com capacidades muitos fracas, incapazes de manter o monopólio da força também podem gerar consequências negativas, como guerra civil e um poder altamente fragmentado, dando espaço para o surgimento de "tiranos locais" (Tilly 2007, p.184).

Mas para alguns teóricos, uma maior capacidade estatal contribuiria para o desenvolvimento da democracia e a diminuição da corrupção. Linz e Stepan (1996, p.17) afirmam que "a democracia é a forma de governança do Estado moderno. Portanto, sem um Estado, nenhuma democracia moderna é possível". 
Mais recentemente, Fukuyama (2014, p.68) também argumentou que antes de um Estado poder ser limitado pela lei ou pela democracia, ele tem de existir, ou seja, deve ser estabelecida uma burocracia e um Poder Executivo centralizados. A democracia liberal de qualidade equilibraria três componentes em uma ordem ideal: primeiro deve vir o Estado, depois o Estado de Direito e por fim a democracia (Fukuyama 2014, p.757).

Fukuyama (2014, p.305) chega às mesmas conclusões de Huntington (1968): as sociedades precisam de ordem antes de regimes democráticos. Os países que hoje apresentam menores graus de corrupção, como a Alemanha, fizeram uma transição autoritária para um sistema político e econômico plenamente modernizado, em vez de se democratizarem logo de início.

Cientistas políticos e sociólogos (Migdal 1988; Tilly 1990; Wade 1990; Evans 1995; Reno 1999; Herbst 2000; La Ferrara \& Bates 2001; Bates 2001) criaram o termo "Estado fraco" para descrever situações em que o Estado tem uma capacidade limitada de tributar e de regular e, consequentemente, de se desenvolver (Acemoglu 2005, pp.1201-1202). Para Fukuyama (2014, pp.380382), está claro que alguns Estados latino-americanos, como a Argentina e a Bolívia, são fracos e, consequentemente, corruptos. Assim como Kurtz (2013, pp.48-54), o Chile e o Uruguai são os Estados mais capazes da América Latina e a Bolívia, o Paraguai e o Haiti os menos capazes, e essa ordem não vem se alterando com o tempo.

Fukuyama (2014) argumenta que os altos graus de corrupção de alguns países da América Latina são consequência da introdução da democracia na região antes da construção dos seus Estados. A falta de capacidade estatal encorajou o clientelismo, onde aqueles que chegavam ao poder por meio de eleições tinham no Estado uma fonte de renda, uma entidade da qual se devia extrair o máximo de benefícios privados. A propagação da competição política democrática antes do fortalecimento do Estado criou incentivos para práticas corruptas na Argentina, no Brasil, no México e na Colômbia, como a nomeação não-meritocrática de cargos públicos e a compra de votos (Fukuyama 2014, p.279).

Nada disso significa que a democracia não é importante. Fukuyama (2014, p.306) ressalva que a accountability, por meio de eleições livres, justas e periódicas é uma coisa boa, independentemente dos efeitos que possa ter na qualidade do governo ou no crescimento econômico. O exercício da escolha política é uma parte importante do desenvolvimento humano, pois o seu exercício reconhece a moral do cidadão e influencia a vida de sua comunidade. A democracia vale a pena, mesmo que as escolhas do povo venham a ser más. Para Fukuyama, a Primavera Árabe de 2011 foi uma demonstração de que a democracia é desejada mesmo em uma parte do mundo onde muitos achavam que havia uma aceitação cultural da ditadura.

Apesar de a democracia ser um valor que deve ser defendido acima de qualquer ganho político, a legitimidade de um regime democrático surge do desempenho do Estado (Fukuyama 2013, p.6). Em muitos países, a democracia está ameaçada porque o Estado é incompetente para cumprir suas funções, como garantir a segurança dos seus cidadãos, defender os direitos de propriedade, oferecer serviços públicos como saúde e educação e fornecer infraestrutura necessária para o desenvolvimento da atividade econômica privada. Sem a presença de um Estado eficiente, as pessoas sonham com uma autoridade poderosa, como um ditador, que não se abale por pressões políticas, não se sujeite a barganhas e defenda os interesses nacionais (Fukuyama 2014, p.73).

Mas substituir uma democracia mal administrada por uma autocracia igualmente incompetente não leva a lugar algum. A maioria dos países em desenvol- 
vimento não seguiu essa sequência ideal. Assim como aconteceu nos Estados Unidos, esses países foram obrigados a construir Estados fortes dentro de uma democracia. Não é possível imitar a Alemanha, que passou por séculos de guerras para atingir o grau de capacidade estatal que se tem hoje. Para Fukuyama (2014), os grupos da sociedade civil e líderes políticos de países democráticos teriam o papel de fortalecer o Estado ao formarem coalizões que lutem pela reforma do setor público e pelo fim da corrupção. Portanto, a construção de um Estado forte é, sobretudo, um ato político. Kurtz (2013, pp.48-54), por exemplo, afirma que os Estados fortes do Chile e do Uruguai são consequências de um consenso relativamente forte entre as elites.

A garantia de prestação de serviços públicos, o cumprimento e alcance das leis e a segurança dos direitos de propriedade dependem do Estado, pois este é a instituição detentora do monopólio da capacidade coerciva de impor a ordem, impedir roubos e fraudes e garantir o cumprimento dos termos dos contratos privados. Assim, o Estado como garantidor da lei e da ordem, da propriedade privada e prestador fundamental de serviços públicos tem o papel de combater a corrupção (Acemoglu \& Robinson 2015, p.71).

Mas a corrupção pode estar, por sua vez, utilizando a capacidade do Estado para fins privados. Rose-Ackerman e Palifka (2016, p.117) argumentam que impostos, regulações, subsídios, fixação de preços e privatizações são exemplos de atividades do setor público, especialmente concernentes à capacidade extrativa do Estado, que os corruptos podem manipular para seu próprio benefício. Como os incentivos fiscais podem ser concedidos a indivíduos e empresas em troca de subornos, os agentes corruptos podem estabelecer altas taxas de impostos para incentivar as propinas. Apesar deste trabalho não descartar a hipótese desta relação de endogeneidade proposta por Rose-Ackerman e Palifka (2016, p.117), alguns estudos empíricos descobriram que a capacidade do Estado, em sua dimensão administrativa, diminui a corrupção mesmo após o controle da endogeneidade, o que evidencia a solidez teórica da direção causal aqui esperada (Rauch \& Evans 2000; Dahlström et al., 2009; 2012; Charron et al., 2017; D’Arcy \& Nistotskaya 2017).

Alguns destes estudos abordaram o impacto das chamadas "burocracias weberianas" nos graus de corrupção. O ideal de administração burocrática de Weber (1919) contém características como uma estrutura formalizada, padronizada, hierárquica e especializada, além de uma equipe profissional com emprego vitalício baseado no mérito e em carreiras organizadas (Dahlström et al., 2009, p.7). Portanto, a ênfase nas burocracias é compatível com a dimensão da capacidade administrativa do Estado, que caracteriza a capacidade estatal pelo grau de profissionalização de seus agentes públicos (Hendrix 2010, p.275).

Entre esses trabalhos está o de Rauch e Evans (2000), que estudaram 35 países em desenvolvimento para medir o impacto de três componentes estruturais das burocracias weberianas - o grau de recrutamento meritocrático, a existência de salários competitivos e o grau de promoção interna e estabilidade de carreira - sobre a corrupção. O grau de recrutamento meritocrático pareceu reduzir o grau de corrupção no conjunto dos países analisados, embora os efeitos das demais variáveis independentes não pudessem ser claramente estabelecidos.

Apesar de pioneiro, o trabalho de Rauch e Evans (2000) não considerou outras variáveis políticas que poderiam impactar a corrupção, como sistema eleitoral e anos de democracia. Dahlström et al. (2009; 2012) preencheram esta lacuna, mas também observaram que características de uma burocracia profissional, especialmente o recrutamento meritocrático, contribuem para a diminuição das atividades corruptas. Isso se manteve mesmo após a inclusão de variáveis políticas e institucionais, além de outras determinantes da corrupção 
propostas pela literatura. Os resultados foram robustos mesmo controlando pela variável dependente defasada, o que indica uma solução considerável para a endogeneidade (Dahlström et al., 2009, p.24; 2012, p.664)

Usando dados de um survey com mais de 18.000 funcionários do setor público em 212 localidades subnacionais da Europa, bem como empregando uma nova medida de risco de corrupção incluindo mais de 1,4 milhão de contratos públicos, Charron et al. (2017) descobriram que quando os incentivos de carreira dos burocratas seguem exclusivamente critérios profissionais, ou seja, não dependem de conexões políticas, o risco de corrupção é significativamente menor. Os resultados foram robustos mesmo após o controle da endogeneidade, ao substituir o grau de meritocracia por variáveis instrumentais (Charron et al., 2017, pp.96-97).

Ao estudar o impacto da democracia sobre a corrupção em 104 países desenvolvidos e em desenvolvimento, entre 1996 e 2003, Rock (2009) incluiu como variável independente o Índice de Eficácia Governamental do Banco Mundial, um dos indicadores mais usados para medir a capacidade administrativa do Estado (Hanson \& Sigman 2013). Rock (2009) argumenta que a inclusão deste índice é uma forma de medir o desenvolvimento da democracia, visto que Linz e Stepan (1996, p.11) apontam que um governo eficaz em sua capacidade extrativa, regulatória e coercitiva é uma condição necessária para o desenvolvimento das democracias modernas. Os resultados sugerem que países de maior eficácia governamental, ou seja, de maior capacidade administrativa, são menos corruptos, mesmo após o controle da endogeneidade por variáveis instrumentais (Rock 2009, pp.14-15).

Usando um novo indicador teórico da capacidade estatal histórica, capaz de medir a extensão e a qualidade dos registros cadastrais de posse de terras, D’Arcy e Nistotskaya (2017) mostraram que são menos corruptos os países em que o Estado desenvolveu mais capacidade de fiscalização antes da democratização. Tem-se, assim, evidências empíricas da plausibilidade de uma suposta sequência ideal - primeiro Estado, depois democracia - proposta em Huntington (1968) e Fukuyama (2014).

Portanto, com a exceção dos estudos supramencionados, há poucas evidências do impacto da capacidade do Estado sobre o grau de corrupção. Os estudos descobriram que a capacidade administrativa diminui a corrupção, mas negligenciaram outras dimensões da capacidade estatal que podem ter efeitos na mesma variável dependente.

$\mathrm{O}$ artigo preenche essa lacuna abordando três dimensões da capacidade do Estado minimamente necessárias para as funções dos Estados modernos: 1) a capacidade extrativa; (2) a capacidade coercitiva e (3) a capacidade administrativa (Hanson \& Sigman 2013). Elas fornecem o que Skocpol (1985, p.16) identificou como os "fundamentos gerais das capacidades do Estado": recursos abundantes, controle administrativo-militar de um território e funcionários leais e qualificados. A seguir, descreve-se os mecanismos causais de cada uma dessas dimensões.

\section{II.1. Hipóteses}

A medida de capacidade estatal mais utilizada na literatura é a taxa de arrecadação de impostos em porcentagem do PIB (Andersen et al., 2014, p.1310). Esta medida reflete a capacidade extrativa do Estado: alcançar a população, coletar e gerenciar informações, possuir agentes confiáveis para gerenciar a receita e garantir o cumprimento da política tributária (Hanson \& Sigman 2013, p.4). 
Uma boa extração fiscal pode indicar que o governo possui recursos que o permitem operar em suas outras funções. Por exemplo, para um monopólio efetivo da violência, ou seja, o exercício da capacidade coercitiva, o exército e a polícia precisam ter recursos extraídos da sociedade (Ottervik 2013, p.10). Assim, a capacidade de um Estado de cobrar impostos é essencial para o fornecimento de bens públicos (Fortin 2012, p.909). Além disso, este pode ser considerado um indicador do grau em que o governo controla a economia (Fukuyama 2013, p.353). Esta medida de capacidade extrativa tem a vantagem de fornecer uma cobertura relativamente alta em comparação a outros indicadores (Arbetman-Rabinowitz \& Kugler 1997). A receita fiscal (ou arrecadação de impostos) é definida como as receitas arrecadadas de impostos sobre receitas e lucros, contribuições para a segurança social, impostos cobrados sobre bens e serviços, impostos sobre a folha de pagamento, impostos sobre a propriedade e transferência de imóveis, entre outros (OECD 2017). A receita tributária total como porcentagem do PIB indica a parcela da produção de um país que é cobrada pelo governo por meio de impostos. Portanto, espera-se que Estados com uma maior arrecadação de impostos possuam mais recursos para combater a corrupção, o que leva à primeira hipótese:

H1: Quanto maior a taxa de arrecadação de impostos, maior o controle da corrupção.

A capacidade administrativa diz respeito à capacidade de desenvolver políticas, produzir e entregar bens públicos e regular a atividade comercial (Hanson \& Sigman 2013, p.4). Uma melhor capacidade de administração pode ser medida pela qualidade de seus burocratas. Uma burocracia profissional, ou seja, de recrutamento meritocrático e imparcial, reduziria a corrupção não selecionando agentes mais competentes, mas introduzindo agentes cujos interesses são diferentes daqueles dos políticos (Dahlström et al., 2012, pp.659$660)$.

A introdução desse tipo de agente dificulta ações oportunistas, como aceitar subornos ou organizar propinas. Embora políticos e burocratas profissionais possam se envolver em comportamentos corruptos, isso requer uma coordenação entre atores de diferentes interesses. $\mathrm{O}$ enfraquecimento dos laços entre políticos e burocratas geralmente diminui a oportunidade de conluio entre eles. Portanto, a segunda hipótese espera que:

H2: Quanto maior a qualidade da burocracia, maior o controle da corrupção.

A capacidade coercitiva do Estado refere-se à faculdade de preservar fronteiras, proteger-se de ameaças externas, manter a ordem interna e conter a violência (Hanson \& Sigman 2013, p.4). Essa definição é consistente com a definição weberiana amplamente aceita do Estado: "O Estado é uma comunidade humana que pretende, com êxito, o uso legítimo da força física dentro de um determinado território" (Weber 1967, p.56). Portanto, a capacidade de coerção é central para o funcionamento do Estado (Fukuyama 2015, p.13). Um aparato coercitivo é necessário não só para combater o crime, mas também para defender a ordem cívica e assegurar processos eleitorais estáveis. Em situações de agitação social, uma disputa pelo monopólio da violência pode levar a conflitos que podem sair do controle e minar os regimes democráticos (Carothers 2007; Dahl 1989, p.47; Tilly 2007, pp.16-18).

Os Estados altamente capacitados convertem seu poder em autoridade, ou seja, na aquiescência voluntária dos cidadãos, com base na crença de que as ações do Estado são legítimas (Fukuyama 2015, p.13). Mas nem todos os cidadãos concordam em obedecer à lei, e mesmo as democracias mais legítimas exigem o poder da polícia para impor o sistema legal. É impossível controlar a corrupção ou cobrar impostos se ninguém for preso por cometer crimes 
(Fukuyama 2015, p.13). Assim, espera-se que seu impacto sobre a corrupção seja maior que o impacto das outras duas dimensões da capacidade do Estado. Portanto, a terceira hipótese deste trabalho é:

H3: Quanto mais gastos militares, maior o controle da corrupção.

\section{Estratégia empírica}

A seção descreve os procedimentos adotados para permitir a replicabilidade do trabalho (King 1995; Janz 2015).

Para minimizar a ineficiência das estimativas resultantes do erro de medição, foram adotados dois procedimentos: 1) o uso de um desenho de pesquisa de série temporal e corte transversal; 2) a estimação de dois painéis de dados (estimador PCSE), um com o Índice CPI como variável dependente e o outro com o CCI, para um teste de robustez.

Para reduzir os problemas de endogeneidade, todas as variáveis independentes foram defasadas em um ano. Isso separa temporariamente os preditores da variável dependente, atenuando o risco de causação inversa (Gerring, Thacker \& Alfaro 2012, p.7). Sem garantir a ausência de uma relação endógena, esse procedimento oferece uma proteção satisfatória (Leipziger 2016, p.13).

A amostra nesse trabalho é de 18 países latino-americanos: Argentina, Bolívia, Brasil, Chile, Colômbia, Costa Rica, El Salvador, Equador, Guatemala, Honduras, México, Nicarágua, Panamá, Paraguai, Peru, República Dominicana, Uruguai e Venezuela.

O período 1996-2015 foi o escolhido por dois motivos. O primeiro é que os dados dos Índices de controle da corrupção, estabilidade política e accountability, todos do Banco Mundial, começaram a ser medidos no ano de 1996. O segundo refere-se ao Índice de Qualidade Burocrática do ICRG, cujos dados estão disponíveis de forma gratuita pelo Banco Mundial também apenas a partir de 1996.

O Quadro 1 sumariza as informações acerca do desenho de pesquisa.

\section{III.1. Variáveis dependentes}

Os indicadores de corrupção utilizados são o Índice de Controle de Corrupção, do Banco Mundial (CCI), e o Índice de Percepção de Corrupção, da ONG Transparência Internacional (CPI). O CCI e o CPI se baseiam em várias fontes de dados que refletem principalmente as opiniões dos empresários internacionais e dos especialistas do país (Kaufmann, Kraay \& Mastruzzi 2003). Os dois conjuntos de dados são considerados os mais confiáveis para comparações transnacionais e cobrem um grande número de países (Jong-sung \& Khagram 2005, p.141).

Esses Índices representam o grau percebido de integridade ou de ausência de corrupção: um número maior indica um grau menor de atividades corruptas. O CCI varia de 0 a 100 (Kaufmann et al., 2010), bem como Índice CPI. Os dados do último foram coletados a partir do do Instituto QOG (Dahlberg et al., 2017). Já os do CCI foram coletados no site do Banco Mundial (2017a).

Os dados apresentam algumas limitações. As medidas para os vários tipos de corrupção não são fornecidas. Além disso, as classificações internacionais com base nas percepções dos entrevistados ou os julgamentos subjetivos de especialistas não são apenas imprecisas, mas também podem ser tendenciosas. Assim, o erro de medição e o viés são possíveis problemas. No entanto, os índices de corrupção baseados nos julgamentos de especialistas e empresários 
Quadro 1 - Síntese das informações do desenho de pesquisa

\begin{tabular}{ll}
\hline & Quadro descritivo \\
\hline Variáveis dependentes & Corruption Perceptions Index (CPI) \\
(Grau de corrupção) & Control of Corruption Index (CCI) \\
Variáveis de interesse & \\
(Capacidade Estatal) & Arrecadação de Impostos (\% PIB) \\
& Qualidade da Burocracia \\
& Despesas Militares (\% PIB) \\
& Accountability \\
Variáveis de Controle & Grau de Democracia \\
& Estabilidade \\
& Educação \\
& PIB per capita (log) \\
& Índice de Gini \\
& Liberdade Econômica \\
& 18 Países da América Latina (1996-2015) \\
Estatística descritiva e inferencial & Estimador de dados de painel PCSE \\
Fontes de dados & Instituto QOG \\
Banco Mundial & Instituto V-Dem \\
& CEPAL \\
& OECD \\
& Polity IV \\
& \\
& \\
& \\
Amstituto Fraser \\
\hline
\end{tabular}

Fonte: Elaboração da autora.

internacionais estão altamente correlacionados com as percepções públicas internas (Jong-sung \& Khagram 2005, p.142).

\section{III.2. Variáveis de Interesse}

Para testar a hipótese de que uma melhor capacidade estatal diminui a corrupção nos países latino-americanos, a variável independente será medida por meio de três proxies, cada uma medindo uma dimensão da capacidade do Estado. A primeira proxy mede a capacidade extrativa, a segunda a capacidade administrativa e a última a capacidade coercitiva. Cada variável será processada em modelos distintos, em conjunto com as variáveis de controle propostas pela literatura, envolvendo possíveis determinantes políticos, demográficos e econômicos da corrupção.

No Modelo 1, a fim de testar a primeira hipótese (H1), utiliza-se a carga tributária medida em receitas fiscais totais recebidas como porcentagem do PIB. Os dados são provenientes da Organização para a Cooperação e Desenvolvimento Econômico (OECD 2017).

Como Hendrix (2010) apontou, nenhuma variável provavelmente modelará adequadamente a capacidade do Estado, mas a arrecadação de impostos em porcentagem do PIB é o indicador que, teoricamente e empiricamente, passa como a mais válida medida geral de capacidade estatal. 
Para testar a segunda hipótese deste trabalho (H2), no Modelo 2 a capacidade administrativa é medida por meio do indicador de qualidade burocrática do International Country Risk Guide (ICRG). Este indicador mede a autonomia da burocracia contra a pressão política e a medida em que existem mecanismos estabelecidos de recrutamento e treinamento. Os dados foram coletados no Banco Mundial (2017b). O índice vai de 0 a 1, com valores maiores significando uma burocracia melhor.

Para a terceira hipótese deste trabalho (H3), no Modelo 3 a capacidade coercitiva é medida por meio dos gastos militares em porcentagem do PIB, medido pelo World Development Indicators, do Banco Mundial (2017c), e coletado pelo banco de dados do Instituto QOG (Dahlberg et al., 2017, p.110).

Essas três medidas têm suas limitações. A arrecadação de impostos (\% PIB) não reporta necessariamente se os esforços na coleta fiscal são eficientes e gerenciados pelo Estado. Além disso, o potencial de arrecadação varia consideravelmente entre os países (Arbetman-Rabinowitz \& Johnson 2007). Da mesma forma, as despesas militares não indicam necessariamente o policiamento efetivo de um determinado território, podendo simplesmente refletir um aparelho militar inchado (Andersen et al., 2014, p.1310). Inclusive, já existem achados que sugerem que o aumento das despesas militares reflete políticas de ditaduras militares (Wintrobe 1990, pp.860-862; Fjelde 2010, p.200). Finalmente, o Índice de Qualidade Burocrática do ICRG foi criticado por sua falta de transparência, baseando-se em avaliações subjetivas por um único codificador e por sua cobertura tendenciosa e limitada (Walle 2005, pp.15-16).

\section{III.3. Variáveis de controle e efeitos esperados}

Numerosas variáveis foram sugeridas como causas da corrupção. Essas variáveis podem ser classificadas em três grandes categorias: explicações políticas, socioculturais e econômicas (Jong-sung \& Khagram 2005, p.137). Portanto, os efeitos das três medidas de capacidade estatal sobre o grau de corrupção serão medidos com a inclusão de uma série de variáveis de controle, potenciais fatores que podem interferir na relação causal. Os fatores políticos são medidas pelo grau de accountability, de democracia e de estabilidade política; o fator social pelo grau de educação; e fatores econômicos, pelo logaritmo natural do PIB per capita ${ }^{2}$, do grau de desigualdade de renda (Índice de Gini) e da liberdade econômica.

\section{III.3.1. Accountability}

${ }^{2}$ O logaritmo natural do PIB é utilizado para controlar distorções na distribuição da variável.
Uma extensa literatura argumenta que as instituições políticas podem afetar a corrupção por meio da acccountability (Lederman, Loayza \& Soares 2005, p.4). Características específicas do sistema político como o grau de competição eleitoral, a existência de freios e contrapesos em diferentes setores do governo e a transparência das atividades governamentais tendem a reduzir a incidência de corrupção. Portanto, espera-se que quanto maior a accountability, maior o controle da corrupção.

A accountability é medida por meio do Índice Voice and Accountability, do Worldwide Governance Indicators (Banco Mundial 2017a). O Índice do Banco Mundial reflete as percepções sobre a medida em que os cidadãos de um país podem participar na seleção do seu governo, bem como a liberdade de expressão, liberdade de associação e uma mídia gratuita (Kaufmann et al., 2010). Foi utilizado o Índice em forma de porcentagem, variando de 0 a 100, com valores maiores correspondendo a mais accountability. 


\section{III.3.2. Democracia}

${ }^{3}$ Em 2015, a taxa regional de pobreza era de $29,2 \%$ dos habitantes (175 milhões) e a taxa de indigência era de 12,4\% (75 milhões) (Cepal 2016, p.18).

${ }^{4}$ ACLP (Alvarez et al., 1996); Arat (1991); Bollen (1980); Polyarchy (Coppedge \& Reinicke 1991); Freedom House (Ryan 1994); Gasiorowski (1996); Hadenius (1992); Polity IV (Marshall \& Jaggers 2001) e Vanhanen (2000).

\section{III.3.3. Estabilidade Política}

O impacto da estabilidade política sobre os graus de corrupção também não tem consenso na literatura. Lederman et al. (2005) descobriram que países mais estáveis politicamente são menos corruptos. Já os resultados de Campante,

Chor \& Do (2009) sugerem que regimes muito estáveis ou muito instáveis corrupção (Sandholtz \& Koetzle 2000; Treisman 2000; Lederman et al., 2005; Pellegrini \& Gerlagh 2008; Bäck \& Hadenius 2008; Montinola \& Jackman 2002). Há estudos que encontraram mais corrupção em países com normas e instituições democráticas mais fracas (Sandholtz \& Koetzle 2000). Similarmente, outros observaram que a exposição a uma democracia ininterrupta de médio a longo prazo estava associada a graus mais baixos de corrupção (Treisman 2000; Lederman et al., 2005; Pellegrini \& Gerlagh 2008). Porém, alguns autores encontraram uma relação não-linear entre as duas variáveis: a democratização parcial pode aumentar a corrupção, mas, uma vez ultrapassado certo limite, a democracia inibiria a corrupção (Bäck \& Hadenius 2008; Montinola \& Jackman 2002).

Diferentemente dos trabalhos acima citados, Jong-sung \& Khagram (2005) verificaram que o impacto da desigualdade sobre a corrupção é maior em democracias. Isso ocorreria porque, em governos autoritários, a opressão pode ser utilizada para se atingir um objetivo; já nas democracias, em que a opressão não é permitida, os poderosos utilizariam a corrupção como substituta da opressão. A América Latina é uma região marcada por uma intensa desigualdade socioeconômica. O’Donnell (1998, p.44) descreve as poliarquias latino-americanas como desiguais, em que considerável parte de suas populações vivem na pobreza ${ }^{3}$. Portanto, como nosso contexto é marcado por alta desigualdade de renda, espera-se que quanto maior o grau de democracia na América Latina, menor o controle da corrupção.

Neste estudo, a democracia foi medida por meio do Índice de Democracia do Polity IV (Marshall \& Elzinga-Marshall 2017). Dahl (1971, p.2) definiu a democracia como "um sistema político cuja característica é a qualidade de ser completamente ou quase completamente responsivo a todos os seus cidadãos". Munck e Verkuilen (2002, p.9), discutindo nove medidas democráticas ${ }^{4}$, incluindo o Polity IV (Marshall \& Elzinga-Marshall 2017), afirmam que as conceituações de democracia nestas avaliações são, em diferentes medidas, influenciadas por Dahl (1971), em cuja obra a democracia consiste em dois atributos: concorrência e participação.

Especialmente, o Polity IV (Marshall \& Elzinga-Marshall 2017) tem alguns méritos. Ele estabelece um elevado padrão quanto ao registro e divulgação das regras de codificação, do processo de codificação e dos dados desagregados (Munck \& Verkuilen 2002, p.21). Registra características de regimes políticos e transições de 1800 a 2014, com dados separados por países e anos, gerando informações para todos os países com população total superior a 500 mil habitantes (167 países em 2014) (Dahlberg et al., 2016, p.91). É uma das fontes mais utilizadas para estudar regimes políticos.

O Polity IV possui uma escala de -10 a +10 , que se divide em: -10 "autocracias totalmente institucionalizadas"; -9 a -6 "autocráticos"; -5 a 0 "anocracias fechadas"; +1 a +5 "anocracias abertas"; +6 a +9 "democracias"; e +10 "democracias totalmente institucionalizadas" (Marshall \& Cole 2014, pp.20-21). 


\section{III.3.4. Educação}

III.3.5. PIB per capita (log)

apresentam graus mais elevados de corrupção quando comparados com aqueles em uma faixa de estabilidade intermediária. Como a média da estabilidade política na região é de $36,59 \%$, espera-se que a estabilidade política diminua o controle da corrupção.

Os dados sobre a estabilidade política foram coletados com base no Índice "Estabilidade Política" (Political Stability) do The Worldwide Governance Indicators (WGI) do Banco Mundial (2017a). Esta medida combina vários indicadores que medem a percepção da probabilidade de que o governo no poder será desestabilizado ou derrubado por meios possivelmente inconstitucionais e/ou violentos, incluindo a violência interna e o terrorismo. A pontuação vai de 0 a 100, em que maior pontuação significa melhores resultados.

Teoricamente, graus mais elevados de educação devem reduzir a corrupção em um país. Indivíduos com mais escolaridade tendem a estar mais comprometidos com as liberdades civis e menos tolerantes com a repressão do governo (Truex 2011). Além disso, mais educação tende a levar a uma maior conscientização sobre os padrões internacionais e, portanto, em tese, devem reduzir a tolerância de uma pessoa pela corrupção. Estudos empíricos mostraram a plausibilidade desta relação (Glaeser \& Saks 2006). Portanto, espera-se que quanto maior o grau de educação, maior o controle da corrupção.

Esta variável de controle será medida em anos de escolaridade entre cidadãos acima de 15 anos de idade. Os dados estão disponíveis no banco de dados do Instituto V-Dem (Teorell et al., 2017), com base no projeto Clio Infra, em parceria com a OECD (Clio-Infra 2014; Coppedge et al., 2017, p.376).

Muitos estudos descobriram que o desenvolvimento econômico é o determinante mais forte para reduzir a corrupção (Voigt \& Gutmann 2015, p.160; Paldam 2002; Treisman 2000; Jong-sung \& Khagram 2005). O PIB per capita (log) será utilizado para medir o desempenho econômico dos países estudados. Logo, a relação esperada é que quanto maior o PIB per capita, maior o controle de corrupção. A Cepal (2017) fornece a fonte dos dados.

III.3.6. Desigualdade Econômica

Estudos descobriram que países mais desiguais são mais corruptos. Isso ocorreria porque altos graus de desigualdade e pobreza inibiriam a capacidade de pobres e da classe média de monitorar as atividades corruptas dos ricos e poderosos (McCarthy \& Zald 1977; Tarrow 1994; Jong-sung \& Khagram 2005). Espera-se, portanto, que quanto maior a desigualdade de renda, menor o controle corrupção.

O Índice de Gini de valor 0 representa igualdade perfeita, enquanto 100 implica significa desigualdade perfeita. Os dados foram obtidos por meio do banco de dados do Instituto V-Dem (V-Dem 2017; Coppedge et al., 2017, p.385; UNU-WIDER 2017).

III.3.7. Liberdade Econômica

Finalmente, a literatura também sugere que a liberdade econômica esteja associada a menores graus de corrupção (Paldam 2002). Estudos empíricos posteriores também corroboraram essa hipótese (Saha et al., 2009). Portanto, também espera-se que quanto maior a liberdade econômica, menor a corrupção. 
O O Índice de Liberdade Econômica (Economic Freedom of the World EFW) do Instituto Fraser (Fraser Institute 2017; Gwartney, Lawson \& Hall 2011) é usado como medida de liberalização econômica. O EFW é dividido em cinco áreas: 1) tamanho do governo; (2) estrutura legal e segurança dos direitos de propriedade; (3) segurança da moeda; (4) liberdade de comércio internacional; (5) regulação do crédito, mão-de-obra e negócios. O Índice, que é publicado anualmente, é calculado tomando-se a média das classificações em cada uma das cinco áreas, todas medidas em uma escala de 0 a 10 . Zero representa o país menos livre e dez, o mais livre.

Embora o Índice EFW agora abranja 141 países, os dados estão disponíveis para aproximadamente 100 países em intervalos de 5 anos, entre 1980 e 2000, e anualmente, a partir de 2001. Para diminuir os casos omissos para de 1996 a 1999, foram repetidos os valores do ano 2000, que consistem na média aritmética da liberdade econômica para o quinquênio 1996-2000.

O Índice EFW tem sido amplamente utilizado por pesquisadores econômicos nos últimos anos (Rode \& Gwartney 2012, p.609). É baseado inteiramente em dados publicados em fontes secundárias, o que significa que pode ser facilmente verificado e duplicado por outros, um recurso de transparência que aumenta sua credibilidade.

\section{III.4. Técnicas}

Primeiramente, serão apresentadas estatísticas descritivas das variáveis que medem a corrupção e a capacidade estatal. Medidas de tendência central e de dispersão visam conhecer as distribuições das variáveis - a análise exploratória dos dados (Exploratory Data Analysis - EDA) (Figueiredo Filho et al., 2011, p.66).

A fim de tornar a análise mais robusta, o banco de dados foi montado em formato de painel, fornecendo um aumento significativo do quantitativo de informações. Possibilita-se, assim, ganhos inferenciais, tendo-se em vista que a pesquisa lida com vários indivíduos durante um período não muito extenso.

Entre as principais vantagens em utilizar dados de painel, destacam-se um maior controle da heterogeneidade individual e mais informações sobre a amostra, permitindo, assim, graus maiores de liberdade e redução da colinearidade entre as variáveis explicativas (Gujarati 2006), além de possibilitar identificar e mensurar efeitos não passíveis de verificação com o uso de séries temporais ou dados de corte transversal (Baltagi 2005).

Para controlar prováveis problemas de heteroscedasticidade e correlação de resíduos entre países, utiliza-se o Modelo econométrico do tipo linear de dados de painel com erros-padrão corrigidos (Panel Corrected Standard Error/PCSE), proposto por Beck e Katz (1995).

\section{Resultados}

IV.1. Análise exploratória dos dados

A subseção traz a análise de estatísticas descritivas para se visualizar e explorar os dados (Tabela 1).

Ao analisar a Tabela 1, verifica-se que o número máximo de casos por variável é de 360. A variável CCI tem menos casos porque o Banco Mundial não possui avaliações para 1997, 1999 e 2000. O Índice de estabilidade política também provém do Banco Mundial, implicando-se as mesmas ausências, mais o ano de 1995, visto que as variáveis independentes foram defasadas em um 
Tabela 1 - Estatística descritiva das variáveis estudadas

\begin{tabular}{lccccc}
\hline Variável & N & Mínimo & Máximo & Média & Desvio Padrão \\
\hline CPI & 329 & 15,00 & 75,00 & 35,77 & 13,81 \\
CCI & 306 & 2,44 & 92,20 & 42,19 & 22,46 \\
Impostos (\%PIB) & 360 & 7,49 & 35,14 & 17,46 & 5,31 \\
Burocracia & 288 & 0,25 & 0,75 & 0,49 & 0,16 \\
Despesas militares & 319 & 0,38 & 4,45 & 1,47 & 0,82 \\
(\%PIB) & & & & & \\
Accountability & 288 & 17,24 & 89,42 & 51,95 & 15,83 \\
Democracia & 360 & $-3,00$ & 10,00 & 7,76 & 1,92 \\
Estabilidade Política & 288 & 0,97 & 82,13 & 36,59 & 18,66 \\
Educação & 324 & 4,27 & 10,42 & 7,05 & 1,30 \\
PIB per capita (log) & 360 & 3,05 & 4,16 & 3,68 & 0,28 \\
Índice de Gini & 355 & 37,70 & 61,90 & 50,88 & 4,57 \\
Liberdade Econômica & 360 & 3,29 & 8,01 & 6,74 & 0,81 \\
\hline
\end{tabular}

Fonte: Elaboração da autora, com base nos dados do Instituto QOG, OECD, Banco Mundial, Instituto V-Dem, Cepal e Instituto Fraser.

ano. O mesmo ocorre com o Índice de Qualidade Burocrática do ICRG. O Índice CPI, as despesas militares e o Índice de Gini possuem alguns casos omissos aleatórios ao longo da amostra.

O gráfico 1 mostra a distribuição dos índices de corrupção do CPI e do CCI. Como podem ser observados, o índice CPI apresenta casos destoantes para o Chile e o Uruguai. De acordo com O'Donnell (1998, p. 44), os bons resultados destes 2 países devem-se aos seus sistemas legais que, de forma geral, funcionam de um modo que a lei alcança todo o território e a maioria das categorias sociais. Nesses países o princípio da lei é razoavelmente efetivo: seus cidadãos são plenos, no sentido de que gozam de direitos políticos e civis.

O Gráfico 2 mostra a distribuição das variáveis que medem a capacidade estatal. Como as medidas de arrecadação de impostos e despesas militares são

Gráfico 1 - Box-plots dos Índices CPI e CCI

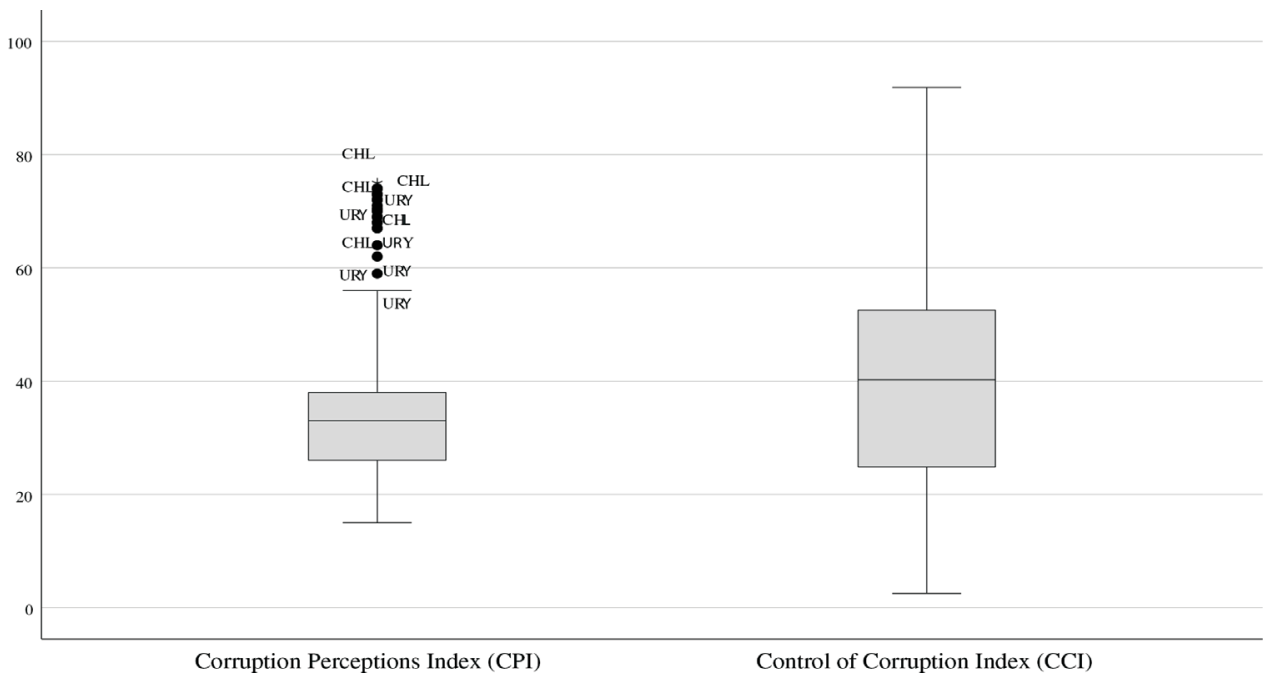

Fonte: Elaboração da autora, com base nos dados dos Índices CPI e CCI (Instituto QOG). 
Gráfico 2 - Box-plots dos Índices de capacidade estatal
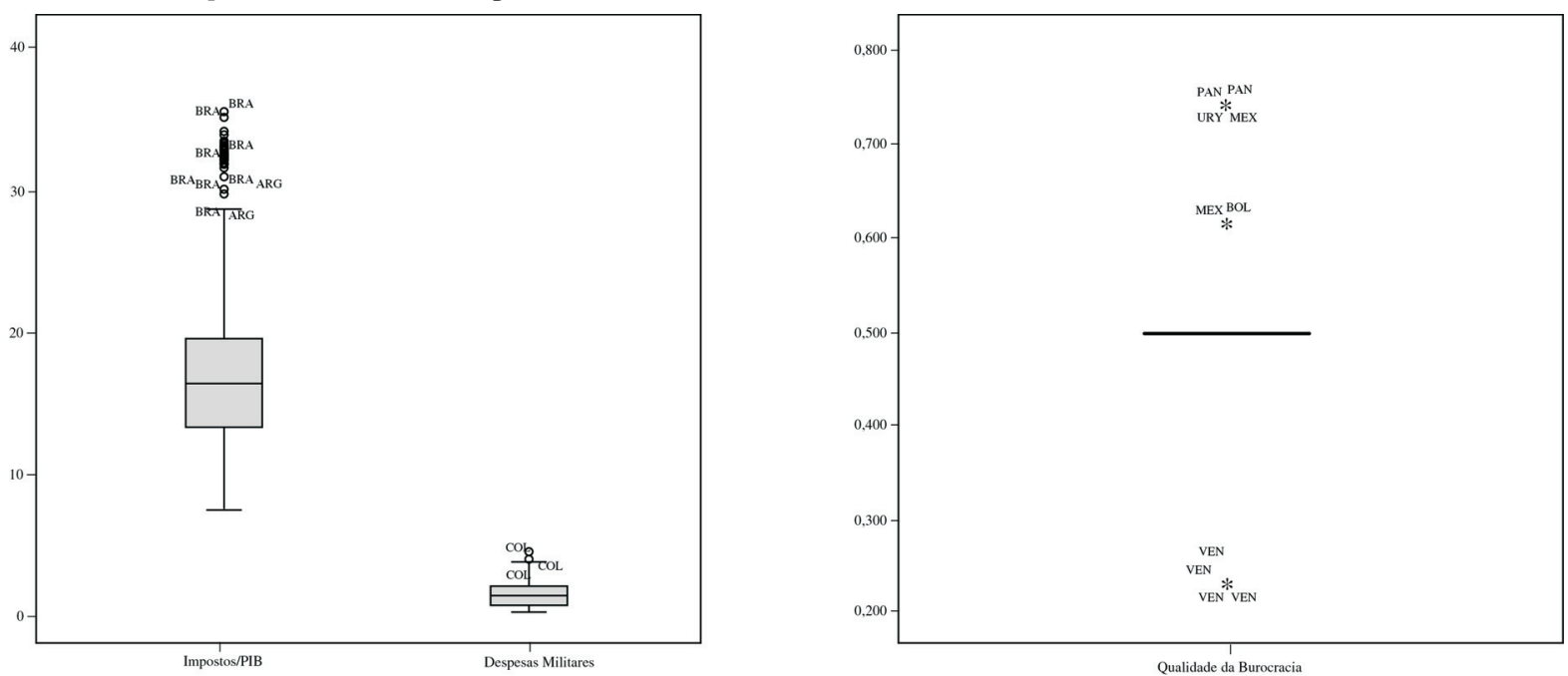

Fonte: Elaboração da autora, com base nos dados do ICRG, OECD e Banco Mundial (Instituto QOG).

medidas em porcentagem do PIB, as distribuições das duas variáveis são mostradas em conjunto, na parte esquerda. O Gráfico 2 destaca os casos destoantes do Brasil e Argentina, para a arrecadação de impostos, e da Colômbia para as despesas militares. Já o Índice de Qualidade da Burocracia apresenta casos destoantes para o Panamá, Uruguai, México e Bolívia, na parte superior, e para a Venezuela, com quatro casos destoantes abaixo da distribuição.

O coeficiente de correlação de Pearson é uma medida de associação linear entre variáveis, variando de -1 a +1 . O sinal indica o sentido em que as varáveis estão associadas. $\mathrm{O}$ valor numérico indica a força da associação. Por exemplo, o valor +1 significa que as variáveis oscilam perfeitamente, estando correlacionadas; ao contrário, -1 significa que as variáveis se opõem por completo (Figueiredo Filho \& Silva Júnior 2009). A Tabela 2 mostra as correlações entre os três índices de capacidade estatal e os dois índices de corrupção utilizados na presente pesquisa.

Todos os valores foram positivos e significantes a $1 \%$, indicando que existe uma associação positiva entre a ausência de corrupção e as diferentes medidas de capacidade estatal. Verifica-se que os Índices de corrupção CPI e CCI estão altamente correlacionados, com o coeficiente de correlação de Pearson medindo 0,951 (p-valor < 0,000). Já os Índices de capacidade estatal, apesar de estarem correlacionados, possuem uma correlação máxima de 0,338

Tabela 2 - Correlações entre os Índices de capacidade estatal e corrupção

\begin{tabular}{lccccc}
\hline & Burocracia & $\begin{array}{c}\text { Impostos/ } \\
\text { PIB }\end{array}$ & $\begin{array}{c}\text { Despesas } \\
\text { Militares }\end{array}$ & CPI & CCI \\
\hline Burocracia & 1 & $0,338^{* * * *}$ & $0,180^{* * *}$ & $0,453^{* * *}$ & $0,507^{* * * *}$ \\
Impostos/PIB & & 1 & $0,211^{* * *}$ & $0,390^{* * *}$ & $0,449 * * *$ \\
Despesas Militares & & & 1 & $0,353^{* * *}$ & $0,390^{* * *}$ \\
CPI & & & & 1 & $0,951^{* * *}$ \\
CCI & & & & & 1 \\
\hline
\end{tabular}

Fonte: Elaboração da autora, com base nos dados do Instituto QOG, da OECD e do Banco Mundial.

*** Significativo a $1 \%$. 
(p-valor < 0,000), entre a qualidade da burocracia e a arrecadação de impostos. A maior correlação apresentada entre corrupção e a capacidade estatal ocorreu entre a qualidade da burocracia e o grau de controle da corrupção (CCI), medindo 0,507 (p-valor $<0,000)$.

IV.2. Resultados do estimador PCSE

A subseção se dedica aos testes de hipótese por meio do estimador de dados em painéis PCSE, proposto por Beck e Katz (1995). A Tabela 3 mostra os resultados das regressões para o Índice CPI da ONG Transparência Internacional como variável dependente.

O Índice de Gini foi a única variável de controle que não mostrou significância estatística em nenhum dos modelos com o Índice CPI como dependente. Portanto, para os modelos propostos, não há suporte para a literatura que infere que países com mais desigualdade de renda são mais corruptos (McCarthy \& Zald 1977; Tarrow 1994; Jong-sung \& Khagram 2005).

No Modelo 1, a taxa de arrecadação de impostos em porcentagem do PIB aparece com um coeficiente positivo e significativo. Controlado pelas demais variáveis propostas pela literatura como possíveis determinantes das ações

Tabela 3 - Resultados do estimador PCSE para o CPI (Transparência Internacional)

\begin{tabular}{|c|c|c|c|}
\hline Variáveis & Modelo 1 & Modelo 2 & Modelo 3 \\
\hline \multirow[t]{2}{*}{ Impostos (\% PIB) } & $0,091 *$ & & \\
\hline & $(0,048)$ & & \\
\hline \multirow[t]{2}{*}{ Burocracia } & & 1,505 & \\
\hline & & $(3,215)$ & \\
\hline \multirow{2}{*}{$\begin{array}{l}\text { Despesas militares } \\
(\% \text { PIB })\end{array}$} & & & $4,648 * * *$ \\
\hline & & & $(0,539)$ \\
\hline \multirow[t]{2}{*}{ Accountability } & $0,339 * * *$ & $0,339 * * *$ & $0,266 * * *$ \\
\hline & $(0,074)$ & $(0,077)$ & $(0,061)$ \\
\hline \multirow[t]{2}{*}{ Democracia } & $-0,788 * *$ & $-0,730 * *$ & $-0,628 * * *$ \\
\hline & $(0,347)$ & $(0,346)$ & $(0,254)$ \\
\hline \multirow[t]{2}{*}{ Estabilidade } & $0,113 * * *$ & $0,124 * * *$ & $0,182 * * *$ \\
\hline & $(0,039)$ & $(0,042)$ & $(0,031)$ \\
\hline \multirow[t]{2}{*}{ Educação } & $1,143 * * *$ & $1,193 * * *$ & $0,635^{* *}$ \\
\hline & $(0,234)$ & $(0,213)$ & $(0,323)$ \\
\hline \multirow[t]{2}{*}{ Pib per capita (log) } & $11,293 * * *$ & $11,114 * * *$ & $12,222 * * *$ \\
\hline & $(2,064)$ & $(2,402)$ & $(1,920)$ \\
\hline \multirow[t]{2}{*}{ Índice de Gini } & $-0,009$ & $-0,000$ & $-0,112$ \\
\hline & $(0,077)$ & $(0,072)$ & $(0,085)$ \\
\hline \multirow{2}{*}{$\begin{array}{l}\text { Liberdade } \\
\text { Econômica }\end{array}$} & $5,131 * * *$ & $4,810 * * *$ & $6,492 * * *$ \\
\hline & $(0,628)$ & $(0,732)$ & $(0,526)$ \\
\hline $\mathrm{N}$ & 240 & 240 & 213 \\
\hline
\end{tabular}

Fonte: Elaboração da autora, com base nos dados do Instituto QOG, OECD, Banco Mundial, Instituto V-Dem, Cepal e Instituto Fraser.

Nota: Erro-padrão entre parênteses; * Significativo a 10\%; ** Significativo a 5\%; *** Significativo a $1 \%$. Todas as regressões incluem um termo constante. 
corruptas, isso sugere que a cada ponto percentual de arrecadação de impostos, gera-se um aumento em torno de $9 \%$ na ausência de corrupção medida pelo Índice CPI da ONG Transparência Internacional. Este resultado indica que a primeira hipótese (H1) deste trabalho não foi rejeitada: Estados com maior capacidade extrativa são menos corruptos.

Os resultados do Modelo 1 sugerem que a accountability possui um impacto positivo no controle da corrupção, como esperado (Lederman et al., 2005). Especificamente, a cada ponto adicional de accountability, há um aumento em torno de $34 \%$ na ausência de corrupção.

A democracia apresentou um coeficiente negativo e significativo, corroborando a hipótese de que a democracia aumenta a corrupção em países de maior desigualdade de renda, como são os casos latino-americanos (Jong-sung \& Khagram 2005). O resultado sugere que a cada ponto adicional de democracia há uma diminuição em torno de $79 \%$ no grau de ausência de corrupção.

A estabilidade política apareceu com um sinal positivo e significativo - um resultado contrário à relação esperada de que baixos graus de estabilidade aumentariam a corrupção (Campante et al., 2009). Os resultados sugerem que a cada ponto adicional de estabilidade política há um aumento em torno de $11 \%$ no grau de controle da corrupção.

A educação, medida em anos de escolaridade entre cidadãos com mais de 15 anos, apareceu com um coeficiente positivo e significativo, sugerindo que um maior grau de educação aumenta o grau de ausência da corrupção, como esperado pela literatura (Truex 2011; Glaese \& Sacks 2006).

O PIB per capita (log) apresentou o maior coeficiente, positivo e significativo, sugerindo que países mais ricos tendem a ser menos corruptos (Voigt \& Gutmann 2015; Paldam 2002). Especificamente, a cada ponto adicional do PIB per capita $(\log )$ tem-se um aumento de aproximadamente $11,29 \%$ na ausência de corrupção.

Concluindo-se a análise do Modelo 1, a liberdade econômica apresentou um coeficiente positivo e significativo, sugerindo que países mais livres economicamente tendem a ser menos corruptos (Paldam 2002; Saha, Gounder \& Su 2009).

O Modelo 2 mede o impacto da capacidade administrativa do Estado, medida pelo Índice de Qualidade da Burocracia do ICRG, sobre o grau de ausência da corrupção, em conjunto com as variáveis de controle do Modelo anterior. Aqui, a variável independente principal não mostrou resultados significativos. Entretanto, os resultados das variáveis de controle foram semelhantes às do Modelo 1: todos os controles mantiveram os coeficientes com o mesmo sinal, a mesma significância e de magnitudes próximas, e o Índice de Gini continuou sem um coeficiente estatisticamente significativo.

O Modelo 3 mediu o impacto da capacidade coercitiva do Estado na ausência de corrupção, com as mesmas variáveis de controle. Os resultados corroboram a terceira hipótese. As despesas militares em porcentagem do PIB apresentaram um coeficiente positivo e significativo, sugerindo que quanto maior a capacidade coercitiva do Estado, maior será o controle da corrupção. Assim como esperado, a medida de um monopólio efetivo da violência (Weber 1967) mostrou ter um maior poder preditivo dos graus de controle da corrupção em relação aos outros indicadores das dimensões administrativa e extrativa da capacidade do Estado.

As variáveis de controle do Modelo 3 apresentaram os mesmos sinais e significância estatística dos modelos 1 e 2. Entretanto, algumas variações devem ser destacadas. O impacto positivo da educação na ausência de corrup- 
ção caiu de aproximadamente 1,14 e 1,19, nos Modelos 1 e 2, para aproximadamente $0,6 \%$ no Modelo 3. Já o impacto positivo do PIB per capita na ausência de corrupção aumentou de aproximadamente 11,29 e 11,11 nos Modelos 1 e 2, para aproximadamente 12,22 no Modelo 3. Por último, diante da capacidade coercitiva do Estado, a liberdade econômica também apresentou coeficientes maiores. O impacto positivo da liberdade econômica na ausência de corrupção aumentou de aproximadamente 5,13 e 4,81 nos Modelos 1 e 2, para aproximadamente $6,49 \%$ no Modelo 3 .

Os sinais negativos e significativos do grau de democracia nos três modelos apresentados sugerem que a democracia tende a aumentar a corrupção em países mais desiguais, como na América Latina. Isso ocorreria porque, nas democracias, os poderosos não dispõem da opressão para realizar seus interesses. Como substituto da opressão, eles usariam práticas de abuso do poder público (Jong-sung \& Khagram 2005). Os coeficientes da estabilidade política apresentaram significância em todos os modelos, mas com sinal positivo. Não se esperava essa relação, que inferia que baixos graus de estabilidade teriam impacto negativo sobre o controle da corrupção (Campante et al., 2009). Os impactos positivos da accountability, do grau de educação, do PIB per capita (log) e da liberdade econômica sobre o controle da corrupção, medidos pelo Índice CPI, são robustos diante de todas as três medidas de capacidade estatal. Esses resultados sugerem que Estados mais ricos, mais livres economicamente, que tenham cidadãos com mais anos de escolaridade e que forneçam instituições políticas que possibilitem uma melhor accountability têm maior probabilidade de serem menos corruptos.

Em suma, os resultados das regressões para o Índice CPI não rejeitaram a hipótese principal: a capacidade estatal mostrou ter impacto positivo no controle da corrupção, mesmo quando controlada por variáveis que poderiam afetar o grau de corrupção. Ao mesmo tempo, os resultados devem ser interpretados com cautela, pois a medida de capacidade administrativa do Estado, o Índice de Qualidade Burocrática do ICRG, não apresentou um coeficiente significativo.

A Tabela 4 mostra os resultados das regressões com o Índice CCI do Banco Mundial como variável dependente, para um teste de robustez dos resultados.

Com o Índice CCI como variável dependente, o grau de democracia não mostrou significância estatística em nenhum dos modelos propostos. Portanto, a expectativa de um impacto negativo da democracia no controle da corrupção como consequência da desigualdade (Jong-sung \& Khagram 2005) não passou no teste de robustez proposto neste trabalho.

No Modelo 1, a medida geral de capacidade estatal mostrou um coeficiente maior que nas regressões com o Índice CPI como variável dependente. Com o Índice do Banco Mundial, o coeficiente mediu 0,51. Com o Índice da Transparência Internacional o coeficiente apresentado foi de apenas 0,09. Isto pode ser um efeito da ligeira diferença na composição dos Índices CPI e CCI. O Índice do Banco Mundial é formado por 5 indicadores. Alguns deles também estão incluídos no CPI, mas quatro deles medem a percepção geral da corrupção, ou seja, entre burocratas não-eleitos e políticos, e um refere-se apenas à corrupção na burocracia. Enquanto isso, o CPI é formado por oito, sendo sete medindo a percepção geral da corrupção e um medindo a corrupção apenas entre os políticos (Hamilton \& Hammer 2017, p.9, pp.14-15).

Portanto, o Índice CPI possui resultados que dão mais peso à corrupção política, enquanto que o CCI dá mais ênfase às ações corruptas dos agentes públicos não-eleitos.

Além disso, o Índice do Banco Mundial poderia estar gerando estimativas maiores ou menores do real grau de controle da corrupção, caso incluísse mais 
Tabela 4 - Resultados do estimador PCSE para o CCI (Banco Mundial)

\begin{tabular}{|c|c|c|c|}
\hline Variáveis & Modelo 1 & Modelo 2 & Modelo 3 \\
\hline \multirow[t]{2}{*}{ Impostos (\% PIB) } & $0,511 * * *$ & & \\
\hline & $(0,114)$ & & \\
\hline \multirow[t]{2}{*}{ Burocracia } & & $16,350 * * *$ & \\
\hline & & $(3,561)$ & \\
\hline \multirow{2}{*}{$\begin{array}{l}\text { Despesas militares (\% } \\
\text { PIB) }\end{array}$} & & & $6,213 * * *$ \\
\hline & & & $(0,641)$ \\
\hline \multirow[t]{2}{*}{ Accountability } & $1,138 * * *$ & $1,129 * * *$ & $0,983 * * *$ \\
\hline & $(0,129)$ & $(0,131)$ & $(0,123)$ \\
\hline \multirow[t]{2}{*}{ Democracia } & $-0,777$ & $-0,292$ & 0,058 \\
\hline & $(0,512)$ & $(0,406)$ & $(0,346)$ \\
\hline \multirow[t]{2}{*}{ Estabilidade } & $-0,231 * * *$ & $-0,152 *$ & $-0,085$ \\
\hline & $(0,085)$ & $(0,084)$ & $(0,067)$ \\
\hline \multirow[t]{2}{*}{ Educação } & $-0,601$ & $-0,668 * *$ & $-0,986 * *$ \\
\hline & $(0,382)$ & $(0,341)$ & $(0,433)$ \\
\hline \multirow[t]{2}{*}{ Pib per capita $(\log )$} & $11,522 * * *$ & $8,798 * *$ & $15,527 * * *$ \\
\hline & $(3,490)$ & $(4,025)$ & $(3,806)$ \\
\hline \multirow[t]{2}{*}{ Índice de Gini } & $-0,166$ & $-0,115$ & $-0,201$ \\
\hline & $(0,164)$ & $(0,123)$ & $(0,129)$ \\
\hline \multirow[t]{2}{*}{ Liberdade Econômica } & $7,168 * * *$ & $4,458 * * *$ & $7,462 * * *$ \\
\hline & $(1,507)$ & $(1,207)$ & $(1,176)$ \\
\hline $\mathrm{N}$ & 198 & 198 & 176 \\
\hline
\end{tabular}

Fonte: Elaboração da autora, com base nos dados do Instituto QOG, OECD, Banco Mundial, Instituto V-Dem, CEPAL e Instituto Fraser.

Nota: Erro-padrão entre parênteses; * Significativo a 10\%; ** Significativo a 5\%; *** Significativo a $1 \%$. Todas as regressões incluem um termo constante.

indicadores em sua composição, visto que usa apenas cinco, enquanto que o CPI é constituído por oito. Portanto, este impacto de $51 \%$ da capacidade extrativa do Estado na variável dependente provavelmente está superestimado ou demonstra que há um maior efeito no controle da corrupção nas burocracias.

Em todos os modelos com o índice CCI como variável dependente, a $a c$ countability manteve o sinal positivo e significativo, passando assim no teste de robustez. Entretanto, os coeficientes para o Índice do Banco Mundial tiveram magnitudes maiores. A accountability mostrou, nos Modelos $1 \mathrm{e} 2$, coeficientes em torno de 1,13 e 1,14 . Nos mesmos modelos, mas com o Índice CPI, os coeficientes mediram aproximadamente 0,34 . No Modelo 3 , a accountability continuou com todos os coeficientes positivos e significativos. Especificamente, a cada ponto adicional de accountability tem-se um aumento de aproximadamente 98\% no grau de ausência de corrupção, medida pelo Índice CCI do Banco Mundial. Como já apontado, a composição do Índice do Banco Mundial é menos heterogênea que a do CPI, assim, o alto coeficiente pode estar superestimando o real impacto da accountability.

Ainda no Modelo 1, a estabilidade política mostrou um coeficiente negativo e significativo, como esperado. Especificamente, a cada ponto adicional de estabilidade política há uma diminuição em torno de $23 \%$ no controle da corrupção. No Modelo 2, a estabilidade política manteve um coeficiente negati- 
vo e significativo, corroborando as expectativas deste trabalho, notando-se, porém, que a magnitude foi um pouco menor: a cada ponto adicional de estabilidade política há uma diminuição em torno de $15 \%$ no controle da corrupção. Com a inclusão da medida de capacidade coercitiva do Estado no Modelo 3, a estabilidade política perdeu a significância estatística.

Os resultados devem ser interpretados com cautela, pois a estabilidade política mostrou coeficientes positivos nos mesmos modelos com o Índice CPI como variável dependente. Portanto, não houve resultados robustos para a corroborar a expectativa de que diante de uma baixa estabilidade, esta contribuiria para o aumento da corrupção (Campante et al., 2009).

O Índice de Gini não mostrou significância em nenhum dos modelos, seja com o Índice CCI, seja com o Índice CPI. Os resultados sugerem que, para todos os modelos, não há suporte para a hipótese de que países com mais desigualdade de renda são mais corruptos (McCarthy \& Zald 1977; Tarrow 1994; Jong-sung \& Khagram 2005).

Já o PIB per capita e a liberdade econômica mantiveram seus coeficientes altos, positivos e significativos em todos os modelos, da mesma forma com o CPI como variável dependente. Portanto, os resultados sugerem que países mais ricos e com mais liberdade econômica são menos corruptos.

O Modelo 2 estima o impacto da capacidade administrativa do Estado, medida pelo Índice de Qualidade da Burocracia do ICRG, controlado pelas demais variáveis. O coeficiente da qualidade burocrática foi de aproximadamente 16,35. Este resultado foi bem diferente com o Índice da Transparência Internacional como variável dependente (Tabela 3), o que pode ser consequência de uma diferença crucial entre os Índices CCI e CPI: o Índice do Banco Mundial contém um indicador exclusivo para a percepção da corrupção entre burocratas, ou seja, entre agentes públicos que não foram eleitos (Hamilton \& Hammer 2017, pp.14-15). Portanto, para o Índice de Qualidade Burocrática, o alto coeficiente faz todo o sentido para o Índice do Banco Mundial, que dá mais peso à corrupção da burocracia de um Estado.

Nos modelos 2 e 3, o grau de educação mostrou um resultado significativo, porém com um sinal negativo, ao contrário do esperado (Truex 2011; Glaeser \& Sacks 2006). Os resultados devem ser interpretados com cautela, pois a educação mostrou um coeficiente positivo com o Índice CPI como variável dependente.

O grau de democracia não mostrou significância estatística em nenhum dos modelos com o Índice CCI. Portanto, a expectativa de que a democracia aumentaria os graus de corrupção em países com maior desigualdade de renda não passou no teste de robustez. Neste caso, aparentemente, o efeito negativo da democracia é mais saliente no grau de controle da corrupção entre políticos, visto que o Índice CPI dá mais ênfase à percepção da corrupção entre agentes públicos eleitos.

No Modelo 3, o impacto da capacidade coercitiva no controle da corrupção foi de aproximadamente 6,2. Portanto, as despesas militares em porcentagem do PIB mostraram coeficientes positivos e significativos, tanto para o CPI como ao CCI como variáveis dependentes, indicando a robustez. Portanto, concretizouse a expectativa de que a capacidade coercitiva do Estado possua mais poder preditivo dos graus de corrupção da América Latina.

Em suma, os resultados sugerem que, para os modelos propostos, a capacidade estatal mostrou ter um impacto positivo nos graus de controle da corrupção, mesmo após a adição de controles por possíveis determinantes políticos e socioeconômicos da corrupção. Novamente, os resultados devem ser interpre- 
tados com cautela, pois a capacidade administrativa do Estado, medida pelo Índice de Qualidade Burocrática do ICRG, não mostrou significância estatística quando a variável dependente foi o Índice CPI (Transparência Internacional).

Em suma, os resultados mostram a importância da inclusão de uma variável-chave para explicar os graus de controle da corrupção: a capacidade coercitiva do Estado. Os achados deste trabalho fazem ainda mais sentido quando se trata dos países latino-americanos.

Hobbes (2005) escreveu, em O Leviatã, que a tarefa primordial do Estado é proteger os cidadãos para evitar a guerra perpétua. Mas a maioria dos Estados da América Latina falharam na tarefa hobbesiana (Mainwaring \& Scully 2008, p.117). Um dos principais problemas sociopolíticos que a região enfrenta até hoje é o aumento da criminalidade (Carreras 2013, p.86). A maioria dos Estados latino-americanos não conseguiram lidar com o aumento da criminalidade ou garantir a implementação e a eficácia de leis e políticas contra a violência. A polícia às vezes está completamente ausente nas áreas mais perigosas. Em outros casos, a polícia responde ao aumento da criminalidade com violência arbitrária, o que agrava a percepção de insegurança entre os cidadãos (Brinks 2008). Além disso, o sistema judicial corrupto e ineficaz da maioria dos países latino-americanos leva à impunidade generalizada.

Desse modo, enquanto os poucos trabalhos empíricos que estudaram o impacto da capacidade estatal sobre a corrupção utilizaram apenas a dimensão administrativa da atuação do Estado como variável independente, o presente estudo mostrou que Estados que detêm um efetivo monopólio da violência, que conseguem manter a ordem interna e punir criminosos também são mais capazes de conter a corrupção.

\section{Conclusões}

A corrupção é um dos maiores desafios às democracias latino-americanas. O abuso do poder público para ganhos privados persiste na maioria dos países da região, excetuando-se Chile, Uruguai e Costa Rica. O artigo identificou as causas da performance no combate à corrupção tanto diferir entre eles, apesar de todos serem democracias eleitorais e compartilharem características institucionais e culturais.

Testou-se também a hipótese de que a capacidade estatal impacta positivamente os graus de controle da corrupção. Visto que os estudos que abordaram a capacidade do Estado como determinante da corrupção utilizaram apenas a dimensão administrativa como variável independente, neste artigo a capacidade estatal foi medida discretamente em suas três dimensões básicas: 1) a arrecadação de impostos em porcentagem do PIB como medida de capacidade extrativa; (2) o Índice de Qualidade da Burocracia do ICRG como medida de capacidade administrativa; (3) os gastos militares em porcentagem do PIB como proxy para a capacidade coercitiva do Estado - por meio de corte transversal e série temporal.

A descrição dos dados e da metodologia recebeu atenção especial para garantir replicabilidade. Para reduzir riscos de viés, a corrupção foi medida por duas variáveis dependentes: o Índice de Percepção da Corrupção da Transparência Internacional (CPI) e o Índice de Controle da Corrupção do Banco Mundial (CCI), consideradas as medidas de ausência de corrupção mais confiáveis (Jong-sung \& Khagram 2005, p.141).

Os resultados sugerem que a hipótese central não foi rejeitada: as três dimensões básicas da capacidade estatal aumentam os graus de controle de corrupção. Além disso, as evidências mostraram que a capacidade coercitiva do 
Estado é mais preditiva dos graus de controle da corrupção na América Latina. Assim, o artigo mostrou que a capacidade de o Estado punir criminosos e garantir o cumprimento e o alcance das leis é central ao combate à corrupção.

Destaca-se que os achados devem ser interpretados com cautela, pois a dimensão administrativa só obteve resultados significativos para o Índice CCI (Banco Mundial) como variável dependente. Isso pode se dar pelas medidas que compõem o indicador: entre as cinco medidas do CCI, uma refere-se exclusivamente à percepção da corrupção entre agentes públicos não-eleitos. Portanto, o impacto da capacidade administrativa do Estado sobre a corrupção pode ser apenas uma consequência do maior peso que o Índice do Banco Mundial dá à corrupção entre burocratas.

A capacidade estatal não deve ser deixada de lado nos estudos que pretendem analisar os determinantes da corrupção, principalmente no que diz respeito à sua dimensão coercitiva: se esta não é uma condição suficiente para diminuir os graus de corrupção de um país, há fortes indícios de que ela é necessária para punir políticos e burocratas corruptos.

Algumas questões ainda permanecem para estudos futuros. Os resultados divergentes entre alguns coeficientes apresentados para os Índices CPI e CCI, como o caso da estabilidade política e o grau de educação, indicam que os próximos estudos devem explorar outros indicadores de percepção da corrupção ou construir índices baseados nos já existentes, para obter resultados mais precisos.

Por fim, o artigo tratou apenas da América Latina - com países de características institucionais e culturais semelhantes. Estudos futuros podem incluir uma maior gama de países e testar se o impacto positivo das diferentes dimensões da capacidade estatal na corrupção também ocorre em países com diferentes sistemas eleitorais, regimes políticos e desenhos institucionais.

Luma Neto do Nascimento (luma.neto@gmail.com) é Doutoranda em Ciência Política pela Universidade Federal de Pernambuco (UFPE) e Bolsista FACEPE. Vínculo Institucional: Programa de Pós-Graduação em Ciência Política, Universidade Federal de Pernambuco, Recife, PE, Brasil

\section{Referências}

Acemoglu, D., 2005. Politics and Economics in Weak and Strong States. Journal of Monetary Economics, 52(7), pp.1199-1226. DOI: 10.1016/j.jmoneco.2005.05.001

Acemoglu, D. \& Robinson, J., 2015. Por que as nações fracassam: as origens do poder, da prosperidade e da pobreza. Brasil: Elsevier.

Andersen, D.; Møller, J.; Rørbæk, L.L. \& Skaaning, S-E., 2014. State Capacity and Political Regime Stability. Democratization, 21(7), pp.1305-1325. DOI: 10.1080/13510347.2014.960204

Arat, Z.F., 1991. Democracy and Human Rights in Developing Countries. Boulder: Lynne Rienner.

Arbetman-Rabinowitz, M. \& Kugler, J., 1997. Political Capacity and Economic Behavior. Boulder: Westview Press.

Arbetman-Rabinowitz, M. \& Johnson, K., 2007. Relative Political Capacity: Empirical and Theoretical Underpinnings. Claremont, CA: Sentia Group.

Bäck, H. \& Hadenius, A., 2008. Democracy and State Capacity: Exploring a J-shaped relationship. Governance, 21(1), pp.1-24. DOI: 10.1111/j.1468-0491.2007.00383.x

Baltagi, B.H., 2005. Econometric Analysis of Panel Data. $3^{\text {th }}$ ed. London: John Wiley \& Sons Ltd.

Barro, R.J. \& Lee, J.W., 2013. A New Data Set of Educational Attainment in the World 1950-2010. Journal of Development Economics, 104, pp.184-198. DOI: 10.1016/j.jdeveco.2012.10.001

Bates, R.H., 2001. Prosperity and Violence. Cambridge, MA: Harvard University Press.

Beck, N. \& Katz, J.N., 1995. What to Do (and Not Do) with Time-Series Cross-Section Data. American Political Science Review, 89(3), pp.634-647. DOI: 10.2307/2082979

Beetham, D.; Carvalho, E.; Landman, T. \& Weir, S., 2008. Assessing the Quality of Democracy. A Practical Guide. Stockholm: International Institute for Democracy and Electoral Assistance.

Brinks, D.M., 2008. The Judicial Response to Police Killings in Latin America: Inequality and the Rule of Law. New York: Cambridge University Press. 
Bollen, K.A., 1980. Issues in the Comparative Measurement of Political Democracy. American Sociological Review, 45(3), pp.370-390. DOI 10.2307/2095172

Bunce, V., 2000. Comparative Democratization: Big and bounded generalizations. Comparative Political Studies, 33(6-7), pp.703-734. DOI: 10.1177/001041400003300602

Campante, F.R.; Chor, D. \& Do, Q.A., 2009. Instability and the Incentives for Corruption. Economics and Politics, 21(1), pp.42-92. DOI: 10.1111/j.1468-0343.2008.00335.x

Carothers, T., 2007. The "Sequencing Fallacy." Journal of Democracy, 18(1), pp.12-27. DOI: 10.1353/jod.2007.0002

Carreras, M., 2013. The Impact of Criminal Violence on Regime Legitimacy in Latin America. Latin America Research Review, 48(3), pp.85-107. DOI: 10.1353/lar.2013.0040,

Coppedge, M. \& Reinicke, W.H., 1991. Measuring Polyarchy. Studies in Comparative International Development, 25(1), pp.51-72. DOI: 10.1007/BF02716905

Coppedge, M; Gerring, J.; Lindberg, S.I.; Skaaning, S.E.; Teorell, J.; Altman, D.; Andersson, F.; Bernhard, M.; Fish, M.S.; Glynn, A.; Hicken, A.; Knutsen, C.H.; Marquardt, K.L.; McMann, K.; Mechkova, V.; Paxton, P.; Pemstein, D.; Saxer, L.; Seim, B.; Sigman, R. \& Staton, J., 2017. V-Dem Codebook v. 7.1. Varieties of Democracy (V-Dem) Project.

Charron, N.; Dahlström, C.; Fazekas, M. \& Lapuente, V., 2017. Careers, Connections, and Corruption Risks: Investigating the impact of bureaucratic meritocracy on public procurement processes. The Journal of Politics, 79(1), pp.89-104. DOI: $10.1086 / 687209$

Dahl, R., 1971. Polyarchy. New Haven: Yale University Press.

Dahl, R., 1989. A. Democracy and Its Critics. New Haven: Yale University.

Dahlberg, S.; Holmberg, S.; Rothstein, B.; Khomenko, A. \& Svensson, R., 2017. The Quality of Government Basic Dataset, version Jan. 2017. University of Gothenburg: The Quality of Government Institute. Disponível em: http://www.qog.pol.gu.se doi:10.18157/QoGBasJan17. Acesso em: 25 jan. 2019.

Dahlström, C.; Lapuente, V. \& Teorell, J., 2009. Bureaucracy, Politics and Corruption. QoG Working Paper Series, 21.

Dahlström, C.; Lapuente, V. \& Teorell, J., 2012. The Merit of Meritocratization: Politics, bureaucracy, and the institutional deterrents of corruption. Political Research Quarterly, 64(3), pp.656-668. DOI: 10.1177/1065912911408109

D’Arcy, M. \& Nistotskaya, M., 2017. State First, then Democracy: Using cadastral records to explain governmental performance in public goods provision. Governance, 30(2), pp.193-209. DOI: 10.1111/gove.12206

Diamond, L. \& Morlino, L., 2005. Assessing the Quality of Democracy. Baltimore: The Johns Hopkins University Press.

Evans, P., 1995. Embedded Autonomy: States and Industrial Transformation. Princeton: Princeton University Press.

Evans, P. \& Rauch, J.E., 1999. Bureaucracy and Growth: A cross-national analysis of the effect of "Weberian" state structures on economic growth. American Sociological Review, 64(5), pp.748-765. DOI: 10.2307/2657374

Figueiredo Filho, D.B. \& Silva Júnior, J.A., 2009. Desvendando os Mistérios do Coeficiente de Correlação de Pearson (r). Revista Política Hoje, 18(8), pp.115-146.

Figueiredo Filho, D.B.; Silva Júnior, J.A. \& Rocha, E., 2011. O que fazer e o que não fazer com a regressão: pressupostos e aplicações do Modelo linear de Mínimos Quadrados Ordinários (MQO). Revista Política Hoje, 20(1), pp.44-99.

Fjelde, H., 2010. Generals, Dictators, and Kings: Authoritarian Regimes and Civil Conflict 1973-2004. Conflict Management and Peace Science, 27(3), pp.195-218. DOI: 10.1177/0738894210366507

Fortin, J., 2012. Is There a Necessary Condition for Democracy? The role of state capacity in postcommunist countries. Comparative Political Studies, 45(7), pp.903-930. DOI: 10.1177/0010414011428587

Fukuyama, F., 2004. State-Building: Governance and World Order in the Twenty-First Century. Ithaca: Cornell University Press.

Fukuyama, F., 2013. Democracy and the Quality of the State. Journal of Democracy, 24(4), pp.5-16. DOI: 10.1353/jod.2013.0074

Fukuyama, F., 2014. Ordem política e decadência política. Lisboa: Publicações D. Quixote.

Fukuyama, F., 2015. Why Is Democracy Performing So Poorly? Journal of Democracy, 26(1), pp.11-20. DOI: 10.1353/jod.2015.0017

Gasiorowski, M.J., 1996. An Overview of the Political Regime Change Dataset. Comparative Political Studies, 29(4), pp.469-483. DOI: 10.1177/0010414096029004004

Gwartney, J.; Lawson, R. \& Hall, J., 2011. Economic Freedom of the World., 2011 Annual Report. Vancouver: Economic Freedom Network.

Gerring, J.; Thacker, S.C. \& Alfaro, R., 2012. Democracy and Human Development. The Journal of Politics, 74(1), pp.1-17. DOI: $10.1017 / \mathrm{s} 0022381611001113$

Glaeser, E.L. \& Saks, R.E., 2006. Corruption in America. Journal of Public Economics, 90(6), pp.1053-1072. DOI: 10.3386/w10821

Gujarati, D.N., 2006. Econometria Básica. Rio de Janeiro: Elsevier.

Hadenius, A., 1992. Democracy and Development. Cambridge, UK: Cambridge University Press.

Hamilton, A. \& Hammer, C., 2017. Can We Measure the Power of the Grabbing Hand? A Comparative Analysis of Different Indicators of Corruption. Policy Research Working Paper. Washington: The World Bank.

Hanson, J.K. \& Sigman, R., 2013. Leviathan's Latent Dimensions: Measuring State Capacity for Comparative Political Research. Manuscrito. Maxwell School of Citizenship and Public Affairs, Syracuse University, New York.

Hendrix, C., 2010. Measuring State Capacity: Theoretical and Empirical Implications for the Study of Civil Conflict. Journal of Peace Research, 47(3), pp.273-285. DOI: 10.1177/0022343310361838 
Herbst, J.I., 2000. States and Power in Africa: Comparative Lessons in Authority and Control. Princeton: Princeton University Press.

Hobbes, T., 2005 [1651]. Leviathan. Adelaide: University of Adelaide Library.

Holmes, S., 1997. When Less State Means Less Freedom. Transitions, 4(4), pp.66-75.

Huber, E.; Rueschemeyer, D. \& Stephens, J.D., 1999. The Paradoxes of Contemporary Democracy: Formal, participatory, and social dimensions. In L. Anderson, ed. Transitions to Democracy. New York: Columbia University Press.

Huntington, S., 1968. Political Order in Changing Societies. New Haven, CT: Yale University Press.

Huntington, S., 1991. The Third Wave: Democratization in the Late Twentieth Century. Norman: University of Oklahoma Press.

Janz, N., 2015. Bringing the Gold Standard into the Classroom: Replication in University Teaching. International Studies Perspectives, March, pp.1-16. DOI: 10.1111/insp.12104

Jong-sung, Y. \& Khagram, S., 2005. A Comparative Study of Inequality and Corruption. American Sociological Review, 70(1), pp.136-157. DOI: 10.1177/000312240507000107

Kaufmann, D.; Kraay, A. \& Mastruzzi, M., 2003. Government Matters III: Governance indicators for 1996-2002. World Bank Policy Research Working Paper, 5430. Disponível em: http://siteresources.worldbank.org/INTWBIGOVANTCOR/Resources/govmatters3_wber.pdf. Acesso em: 25 jan. 2019.

Kaufmann, D.; Kraay, A. \& Mastruzzi, M., 2010. The Worldwide Governance Indicators: A Summary of Methodology, Data and Analytical Issues. World Bank Policy Research Working Paper, 5430. Disponível em: http://papers.ssrn.com/sol3/papers.cfm?Abstract_id=1682130. Acesso em: 08.mai.2017.

La Ferrara, E. \& Bates, R.H., 2001. Political Competition in Weak States. Economics and Politics, 13(2), pp.159-184. DOI: 10.1111/1468-0343.00088

Lederman, D.; Loayza, N.V. \& Soares, R.R., 2005. Accountability and Corruption: Political Institutions Matter. Economics and Politics, 17(1), pp.1-35. DOI: 10.1111/j.1468-0343.2005.00145.x

Leipziger, L.E., 2016. Democracy and State Capacity Revisited: An Investigation of Democracy's Consequences for State Capacity. Users Working Paper Series, pp.1-21. The Varieties of Democracy Institute.

Linz, J.J. \& Stepan, A., 1996. Problems of Democratic Transition and Consolidation. Baltimore: Johns Hopkins University Press.

Mazzuca, S.L., 2010. Access to Power Versus Exercise of Power Reconceptualizing the Quality of Democracy in Latin America. Studies in Comparative International Development, 45(3), pp.334-357. DOI: 10.1007/s12116-010-9069-5

Mazucca, S.L. \& Munck, G.L., 2014. State or Democracy First? Alternative perspectives on the state-democracy nexus. Democratization, 21(7), pp.1221-1243. DOI: 10.1080/13510347.2014.960209

McCarthy, J. \& Zald, M., 1977. Resource Mobilization and Social Movements: A Partial Theory. Social Movements in an Organizational Society, 82(6), pp.1212-1241.

Migdal, J.S., 1988. Strong Societies and Weak States: State-Society Relations and State Capabilities in the Third World. Princeton: Princeton University Press.

Møller, J. \& Skaaning, S-E., 2013. Democracy and Democratization in Comparative Perspective: Conceptions, Conjunctures, Causes, and Consequences. London: Routledge.

Montinola, G.R. \& Jackman, R.W., 2002. Sources of Corruption: A cross-country study. British Journal of Political Science, 32(1), pp.147-170. DOI: 10.1017/s0007123402000066

Munck, G. \& Verkuilen, J., 2002. Conceptualizing and Measuring Democracy: Evaluating alternative indices. Comparative Political Studies, 35(1), pp.5-34. DOI: 10.1177/001041400203500101

O’Donnell, G., 1998. Poliarquias e a (in)efetividade da lei na América Latina. Novos Estudos, 51, pp.37-61.

O’Donnell, G.; Vargas, C.J. \& Iazzetta, O.M., 2004. The Quality of Democracy. Theory and Applications. South Bend: University of Notre Dame Press.

Ottervik, M., 2013. Conceptualizing and Measuring State Capacity. QoG Working Paper Series, 20.

Paldam, M., 2002. The Cross-Country Pattern of Corruption: Economics, culture and the seesaw dynamics. European Journal of Political Economy, 18(2), pp.215-240. DOI: 10.1016/s0176-2680(02)00078-2

Pellegrini, L. \& Gerlagh, R., 2008. Causes of Corruption: A survey of cross-country analyses and extended results. Economics of Governance, 9(3), pp.245-263. DOI: 10.1007/s10101-007-0033-4

Przeworski, A., 1995. Sustainable Democracy. Cambridge, UK: Cambridge University Press.

Rauch, J. \& Evans, P., 2000. Bureaucratic Structure and Bureaucratic Performance in Less Developed Countries. Journal of Public Economics, 75(1), pp.49-71. DOI: 10.1016/s0047-2727(99)00044-4

Reno, W., 1999. Warlord Politics and African States. Boulder: Lynn Weiner Publishers.

Roberts, C. \& Sherlock, T., 1999. Bringing the Russian State Back In: Explanations of the derailed transition to market democracy. Comparative Politics, 31(4), 477-498. DOI: 10.2307/422241

Rock, M.T., 2009. Corruption and Democracy. The Journal of Development Studies, 45(1), pp.55-75. DOI: $10.1080 / 00220380802468579$

Rode, M. \& Gwartney, J.D., 2012. Does Democratization Facilitate Economic Liberalization? European Journal of Political Economy, 28(4), pp.607-619. DOI: 10.1016/j.ejpoleco.2012.07.001

Rose-Ackerman, S. \& Palifka, B.J., 2016. Corruption and Government: Causes, Consequences, and Reform. Cambridge, UK: Cambridge University Press. 
Rothstein, B. \& Teorell, J., 2008. What Is Quality of Government? A Theory of Impartial Government Institutions. Governance, 21(2), pp.165-190. DOI: 10.1111/j.1468-0491.2008.00391.x

Ryan, J.E., 1994. Survey Methodology. Freedom Review, 25(1), pp.9-13.

Saha, S.; Gounder, R. \& Su, J.J., 2009. The Interaction Effect of Economic Freedom and Democracy on Corruption: A panel cross-country analysis. Economics Letters, 105(2), pp.173-176. DOI: 10.1016/j.econlet.2009.07.010

Sandholtz, W. \& Koetzle, W., 2000. Accounting for Corruption: Economic structure, democracy, and trade. International Studies Quarterly, 44(1), pp.31-50. DOI: 10.1111/0020-8833.00147

Skocpol, T., 1985. Bringing the State Back In: Strategies of analysis in current research. In P. Evans et al., eds. Bringing the State Back In. Cambridge, UK: Cambridge University Press.

Suleiman, E., 1999. Bureaucracy and Democratic Consolidation: Lessons from Eastern Europe. In L. Anderson, ed. Transition to Democracy. New York: Columbia University Press.

Tarrow, S., 1994. Power in Movement: Social Movements, Collective Action, and Politics. Cambridge, UK: Cambridge University Press.

Teorell, J.; Coppedge, M.; Skaaning, S.R. \& Lindberg, S.I., 2017. Measuring Electoral Democracy with V-Dem Data: Introducing a New Polyarchy Index. V-Dem Working Paper, 25. DOI: 10.2139/ssrn.2740935

Tilly, C., 1990. Coercion, Capital and European States, AD 990-1990. Cambridge, MA: Blackwell.

Tilly, C., 2007. Democracy. Cambridge, UK: Cambridge University Press.

Todaro, M.P. \& Smith, S.C., 2015. Economic Development. $12^{\text {th }}$ ed. New Jersey: Pearson.

Treisman, D., 2000. The Causes of Corruption: A cross-national study. Journal of Public Economics, 76(3), pp.399-457. DOI: 10.1016/s0047-2727(99)00092-4

Truex, R., 2011. Corruption, Attitudes, and Education: Survey evidence from Nepal. World Development, 39(7), pp.1133-1142. DOI: 10.1016/j.worlddev.2010.11.003

Walle, S.V, 2005. Measuring Bureaucratic Quality in Governance Indicators. In $8^{\text {th }}$ Public Management Conference. Los Angeles.

Vanhanen, T., 2000. A New Dataset for Measuring Democracy, 1810-1998. Journal of Peace Research, 37(2), pp.251-265. DOI: $10.1177 / 0022343300037002008$

Voigt, S. \& Gutmann, J., 2015. On the Wrong Side of the Law: Causes and Consequences of a Corrupt Judiciary. International Review of Law and Economics, 43, pp.156-166. DOI: 10.1016/j.irle.2014.04.005

Wade, R., 1990. Governing the Market: Economic Theory and the Role of Government in East Asian Industrialization. Princeton: Princeton University Press.

Wang, X., 1999. Mutual Empowerment of State and Society: Its nature, condition, mechanisms, and limits. Comparative Politics, 31(2), pp.231-249. DOI: 10.2307/422146

Weber, M., 1967 [1919]. A política como vocação. In H.H. Gerth \& C. Wright Mills, eds. Max Weber - Ensaios de Sociologia. Rio de Janeiro: Livros Técnicos e Científicos.

Wintrobe, R., 1990. The Tinpot and the Totalitarian: An Economic Theory of Dictatorship. American Political Science Review, 84(3), pp.849-872. DOI: $10.2307 / 1962769$

\section{Outras fontes}

Banco Mundial, 2017a. The Worldwide Governance Indicators (WGI) Project. Disponível em: http://info.worldbank.org/governance/wgi/\#home. Acesso em: 20 jun. 2017.

Banco Mundial, 2017b. Political Risk Services International Country Risk Guide. Disponível em: info.worldbank.org/governance/wgi/pdf/PRS.xlsx. Acesso em: 20 jun. 2017.

Banco Mundial, 2017c. World Development Indicators. Disponível em: https://datacatalog.worldbank.org/dataset/world-development-indicators. Acesso em: 25 jan. 2019.

Cepal, 2016. Panorama Social de América Latina. Disponível em: http://repositorio.cepal.org/bitstream/handle/11362/39965/S1600175_es.pdf?sequence=4\&isAllowed=y. Acesso em: 1 fev. 2017.

Cepal, 2017. Producto interno bruto (PIB) total anual por habitante a precios constantes en dólares. Disponível em: http://interwp.cepal.org/sisgen/ConsultaIntegrada. asp?idIndicador=2206\&idioma=e. Acesso em: 20 maio 2017.

Clio-Infra, 2014. Datasets. Disponível em: http://www.clio-infra.eu/ . Acesso em: 27 maio. 2014.

Fraser Institute, 2017. Economic Freedom Rankings. Disponível em: http://fraserinstitute.org/economic-freedom/dataset. Acesso em: 15 jun. 2017.

OCDE, 2017. Government at a Glance. Disponível em: https://www.oecd.org/gov/government-at-a-glance-2017-highlights-en.pdf. Acesso em: 25 jan. 2019.

UNU-WIDER, 2017. World Income Inequality Database (WIID3.4). Disponível em: https://www.wider.unu.edu/database/world-income-inequality-database-wiid34. Acesso em: 5 abr. 2017.

V-DEM, 2017. V-Dem Data - Version 7.1. Disponível em: https://www.v-dem.net/en/data/data-version-7-1/. Acesso em: 15 jul. 2017. 
More state capacity, less corruption? An analysis for Latin America (1996-2015)

ABSTRACT Introduction: The greater the state capacity, the less corruption? This article tests the hypothesis that state capacity reduces levels of corruption in Latin America in the period between 1996 and 2015. Materials and methods: For a robustness test, the level of absence of corruption was measured by two different indices, the CPI index of Transparency International and the CCI index of the World Bank. State capacity was measured through tax collection as a percentage of GDP; the State's coercive capacity was measured by military expenditures as a percentage of GDP; administrative capacity was measured through the bureaucratic quality index of the ICRG. For the hypothesis tests two PCSE data panels were estimated, one with the CPI as dependent variable and another with the CCI as dependent variable. Results: The results suggest that the main hypothesis was confirmed: the state capacity increases the levels of absence of corruption, even after the test of robustness for the two measures of absence of corruption and with controls for possible political and socioeconomic determinants of corruption suggested in the literature. However, the measure of administrative capacity only achieved significance with the $\mathrm{CCl}$ index as a dependent variable. Discussion: This research will contribute to the literature when analyzing a new determinant of corruption, state capacity, showing that this should be included in the studies that intend to analyze its causes.

KEYWORDS: state capacity; administrative capacity; coercive capacity; corruption; Latin America.

This is an Open Access article distributed under the terms of the Creative Commons Attribution Non-Commercial License which permits unrestricted non-commercial use, distribution, and reproduction in any medium provided the original work is properly cited. 